Tropical Journal of Pharmaceutical Research October 2011; 10 (5): 587-594

(C) Pharmacotherapy Group,

Faculty of Pharmacy, University of Benin,

Benin City, 300001 Nigeria.

All rights reserved.

Available online at http://www.tjpr.org

Research Article

http://dx.doi.org/10.4314/tjpr.v10i5.7

\title{
Subacute Oral Toxicity Assessment of Alchornea cordifolia (Schumach and Thonn) Müll Arg (Euphorbiaceae) Extract in Rats
}

\section{Charles Ansah*, Emmanuel Oppong and Eric Woode}

Department of Pharmacology, Faculty of Pharmacy and Pharmaceutical Sciences, College of Health Sciences, Kwame Nkrumah University of Science and Technology, Kumasi, Ghana.

\begin{abstract}
Purpose: To assess Alchornea cordifolia, a medicinal plant with numerous biological actions and uses in traditional medicine, for possible toxicity in rats.

Methods: The probable effect of the ethanol extract of Alchornea cordifolia (250 - $2000 \mathrm{mg} / \mathrm{kg}$, p.o.) by gavage was evaluated on blood cellular elements and chemistry, as well as on the weight and histology of vital organs of male adult Spraque-Dawley rats.

Results: Daily administration of the extract for two weeks did not cause significant changes in most haematological indices and blood chemistry. However, a dose-dependent increase $(p<0.01)$ in neutrophils was observed. Relative organ weights were comparable in control and treated groups. Histopathological assessment of liver sections of treated-rats showed normal architecture at doses < $1000 \mathrm{mg} / \mathrm{kg}$. However, in animals treated with 1000 and $2000 \mathrm{mg} / \mathrm{kg}$, cloudy swelling of hepatocytes with vacuolar and hydropic degeneration were evident. Kidney architecture at all dose levels was normal.

Conclusion: The results of the study show that administration of the ethanol extract of Alchornea cordifolia to male adult rats by gavage evoked histopathologic changes in the liver at doses > 1000 $\mathrm{mg} / \mathrm{kg}$. These findings call for caution in the use of Alchornea cordifolia especially in high doses.
\end{abstract}

Keywords: Alchornea cordifolia, Rats, Subacute oral toxicity, Neutrophils, Hepatocytes, Hydropic denegeration 


\section{INTRODUCTION}

The World Health Organization (WHO) estimates that nearly $70 \%$ of the world population depend on traditional medicine, especially medicinal plants, for their primary health care needs [1]. Concerns have, however, been raised by researchers regarding the safety of such botanical products. Alchornea cordifolia (Schumach and Thonn) Müll. Arg. (Euphorbiaceace) is a shrub found along the coastal regions of West Africa. Traditionally, pulverized leaves of Alchornea cordifolia are used to treat wounds, sores and cuts [2]. Phytochemical analysis of the leaves has identified the presence of several compounds including flavonoids [3]. Reports on the biological activity of Alchornea suggest that it is antibacterial [4] spasmolytic [3], antiinflammatory [5], hepato-protective [6], antidiarrhoeal [7], antioxidant [8] and antimicrobial [9]. We reported previously on the propensity of Alchornea alcoholic extract to provoke hepatic damage in mice [10]. In view of possible interspecies variation in response to toxic agents, we were prompted to investigate the effect of Alchornea extract in rats with the objective of expanding the knowledge on the safety profile of this popular medicinal plant.

\section{EXPERIMENTAL}

\section{Collection and identification of plant material}

The fresh leaves of the plant Alchornea cordifolia were obtained from the Kwame Nkrumah University of Science and Technology botanical gardens and authenticated by Dr. Kofi Annan of the Department of Pharmacognosy, Faculty of Pharmacy and Pharmaceutical Sciences, College of Health Sciences, Kwame Nkrumah University of Science and Technology, Kumasi, Ghana. A voucher specimen (No. FPPS-DCOL. 123) was kept at the herbarium of the Department of Pharmacognosy, Faculty of Pharmacy and Pharmaceutical
Sciences, College of Health Sciences, Kwame Nkrumah University of Science and Technology, Kumasi, Ghana.

\section{Preparation of Alchornea cordifolia extract}

The leaves of the plant were sun-dried for one week and then powdered in a hammer mill. The powder $(800 \mathrm{~g})$ was extracted by cold maceration with $70 \%$ alcohol $(5 \mathrm{~L})$. The alcohol was evaporated in a rotary evaporator attached to a thermochiller (Buchi 700 , Recirculation chiller) at a temperature of $20{ }^{\circ} \mathrm{C}$. The residue was freeze-dried to obtain a brown sample of the crude extract (yield: $10.80 \% \mathrm{w} / \mathrm{w}$ ), subsequently referred to as the extract in this study.

\section{Experimental animals}

Male adult Spraque-Dawley rats (130 - $195 \mathrm{~g})$ were purchased from Noguchi Memorial Institute for Medical Research, University of Ghana, Legon, Accra, Ghana and maintained in the animal house of the Department of Pharmacology, Kwame Nkrumah University of Science and Technology, Kumasi, Ghana. They were housed in groups of six in stainless steel cages $(34 \times 47 \times 18 \mathrm{~cm})$ with soft wood shavings as bedding, fed with normal commercial pellet diet (GAFCO, Tema, Ghana) and given water ad libitum. The animals were humanely handled throughout the experiment in accordance with ethical guidelines for the care of laboratory animals (EEC directive of 1986:86/609 EEC) [11]. The protocols were approved (Ref. No. D/COL/ECA-8-2010) by the Department's Ethics Committee.

\section{Subacute treatment}

Male Spraque-Dawley rats (130 - $195 \mathrm{~g}$ ) were obtained and divided into five groups $(n=6)$. The groups received 250, 500, 1000, 2000 $\mathrm{mg} / \mathrm{kg}$ extract in $2 \%$ tragacanth (p.o.) daily for 2 weeks. The control group received tragacanth $2 \%$ only throughout the 2-week period. The animals were monitored closely 
for signs of toxicity, and at the end of the twoweek period, the rats were euthanized by cervical dislocation and blood was collected into tubes for analysis.

\section{Blood analysis}

Haematological analyses were performed on whole blood collected into tubes with ethylenediaminetetraacetic acid (EDTA). White blood cell (WBC), lymphocytes (LYM), mid cells (MID), neutrophils (NEU), red blood cells (RBC), haemoglobin concentration (HB), haematocrit (HCT), mean corpuscular volume (MCV), mean corpuscular haemoglobin (MCH), mean corpuscular haemoglobin concentration (MCHC), red cells distribution weight (RDW) and platelets (PLT) were determined by an automatic analyzer (CELL DYN 1700, Abbott Diagnostics Division, Abbott Laboratories, Abbott Park, IL, USA).

\section{Biochemical analysis}

Biochemical analyses were performed on serum obtained after centrifugation of whole blood (without anticoagulant) at $3000 \mathrm{rpm}$ for 5 min. Determination of total proteins; total bilirubin, indirect bilirubin, albumin, globulin and $A / G$ ratio were performed using an automatic analyzer (Random Access Chemistry System ATAC 8000, élan diagnostic laboratories, Brea, CA, USA). Levels of the liver enzymes alanine aminotransferase (ALT), alkaline phosphatase (ALP) and $Y^{-}$glutamyl aminotransferase (GGT) were also determined. Analysis for blood urea nitrogen (BUN), creatinine, sodium, potassium and chloride were performed as well.

\section{Organ weight determination}

The following organs were quickly removed and individually weighed: liver, spleen, kidneys, heart, stomach, testes and lungs. Macroscopic appearances of the organs were observed and the relative weight of each organ was calculated. The liver and kidney were fixed in $10 \%$ formalin for histopathological studies.

\section{Histopathological examination}

For microscopic examination, whole liver and kidney were fixed in $10 \%$ neutral buffered formalin. Sections $(2.0 \mathrm{~mm})$ were placed in tissue preparation cassettes and processed with an auto processor (Microm STP120, Spain) for embedding in paraffin. Tissue sections of $7.0 \mu \mathrm{m}$ were cut and stained with hematoxylin and eosin ( $\mathrm{H}$ and $\mathrm{E})$.

\section{Statistical analysis}

Results were expressed as mean \pm standard error of mean (SEM). Statistical analysis was performed by one-way ANOVA using Graph Pad Prism for Windows version 4.02 (Graph Pad software, San Diego, CA, USA), followed by Neuman Keuls test to evaluate significant differences between the groups. Differences were considered significant at $p<0.05$

\section{RESULTS}

\section{Behavior of the treated animals}

When the animals were observed closely over the period for signs of toxicity, no abnormal behavior, motor or neurological disorder was noticed. The treatment did not affect the gastrointestinal or respiratory systems. There was no mortality or changes in locomotor activity. Food and water intake were normal and there were no significant differences between the body weight of the treated and control groups over the 14-day period (Figure 1).

\section{Blood analysis}

For haematological evaluation, there was no significant change in most of the parameters analyzed (Table 1). However, there was a significant dose-dependent increase in the neutrophil count of animals treated with the extract compared to the control. The level of lymphocyte decreased in rats treated with $2000 \mathrm{mg} / \mathrm{kg}$ compared to the control (Table 1). 


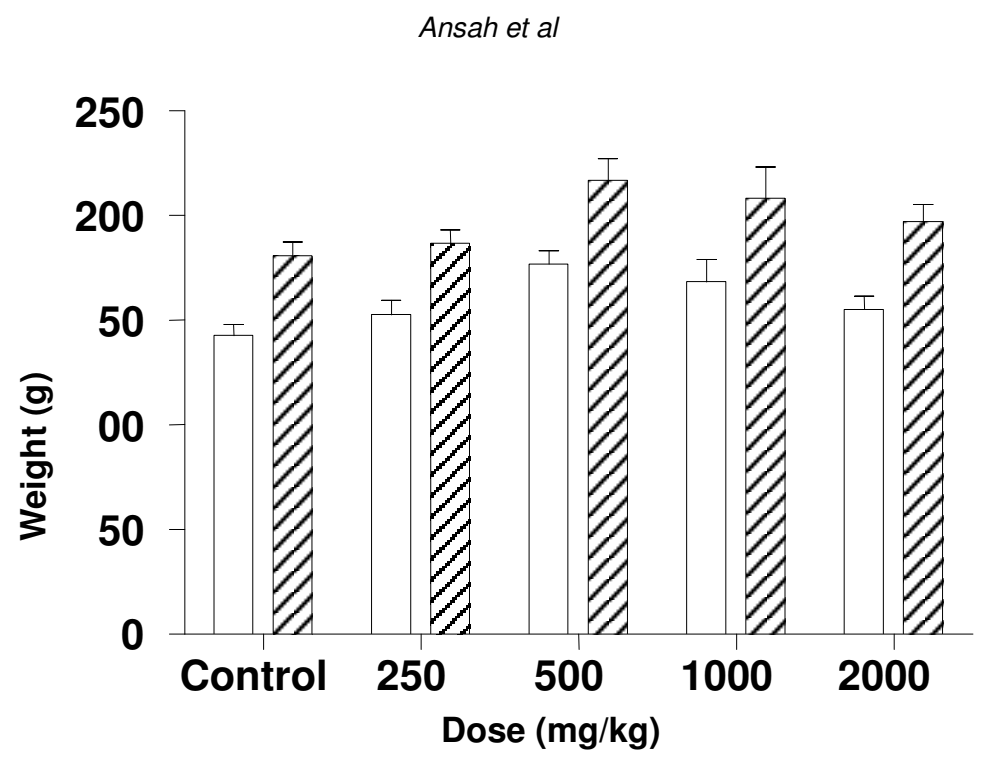

Fig 1: Weight of rats before (plain bars) and after (striped bars) 14-day treatment with Alchornea cordifolia extract.

Table 1: Effect of Alchornea cordifolia on haematological indices in rats treated for two weeks.

\begin{tabular}{|c|c|c|c|c|c|}
\hline \multirow[b]{2}{*}{ Parameter } & \multicolumn{5}{|c|}{ Dose (mg/kg) } \\
\hline & Control & 250 & 500 & 1000 & 2000 \\
\hline$\overline{W B C}(\mathrm{~K} / \mu \mathrm{L})$ & $10.34 \pm 1.77$ & $8.70 \pm 1.01$ & $9.58 \pm 0.38$ & $8.88 \pm 0.98$ & $8.08 \pm 1.20$ \\
\hline LYM (\%) & $83.63 \pm 3.07$ & $81.94 \pm 1.11$ & $76.70 \pm 1.69$ & $76.52 \pm 2.59$ & $71.64 \pm 2.35^{*}$ \\
\hline MID (\%) & $13.03 \pm 1.87$ & $13.32 \pm 0.35$ & $16.10 \pm 0.93$ & $15.62 \pm 2.02$ & $17.34 \pm 2.00$ \\
\hline NEU (\%) & $3.35 \pm 1.42$ & $4.74 \pm 1.01$ & $7.20 \pm 0.88^{*}$ & $7.86 \pm 0.73^{*}$ & $11.02 \pm 0.86^{\star *}$ \\
\hline $\mathrm{RBC}(\mathrm{M} / \mu \mathrm{L})$ & $6.01 \pm 0.20$ & $5.84 \pm 0.07$ & $6.00 \pm 0.32$ & $5.98 \pm 0.21$ & $5.77 \pm 0.14$ \\
\hline $\mathrm{HB}(\mathrm{g} / \mathrm{dL})$ & $13.48 \pm 0.51$ & $13.83 \pm 0.47$ & $13.02 \pm 0.51$ & $13.20 \pm 0.40$ & $12.62 \pm 0.26$ \\
\hline HCT (\%) & $35.80 \pm 1.43$ & $35.20 \pm 0.91$ & $34.75 \pm 1.80$ & $34.15 \pm 1.09$ & $32.78 \pm 0.47$ \\
\hline MCV (fl) & $59.62 \pm 1.47$ & $59.97 \pm 0.96$ & $57.95 \pm 0.99$ & $57.12 \pm 0.80$ & $56.84 \pm 0.66$ \\
\hline $\mathrm{MCH}(\mathrm{pg})$ & $22.44 \pm 0.60$ & $22.98 \pm 0.29$ & $21.80 \pm 0.54$ & $22.08 \pm 0.35$ & $22.16 \pm 0.24$ \\
\hline $\mathrm{MCHC}(\mathrm{g} / \mathrm{dL})$ & $37.66 \pm 0.57$ & $38.14 \pm 0.49$ & $37.58 \pm 0.68$ & $38.65 \pm 0.10$ & $39.02 \pm 0.24$ \\
\hline RDW (\%) & $15.86 \pm 0.66$ & $16.02 \pm 0.45$ & $15.30 \pm 0.32$ & $14.67 \pm 0.29$ & $16.12 \pm 0.34$ \\
\hline $\operatorname{PLT}(\mathrm{K} / \mu \mathrm{L})$ & $276.40 \pm 95.49$ & $302.20 \pm 60.01$ & $401.70 \pm 65.66$ & $348.50 \pm 69.70$ & $446.20 \pm 99.82$ \\
\hline
\end{tabular}

Values are expressed as means $\pm \operatorname{SEM}(n=6) ;\left(^{*}\right)$ indicates significant $(p<0.05)$ and ${ }^{* *}(p<0.01)$ compared to control (Newman Keuls test)

\section{Serum biochemical analysis}

Biochemical parameters determined did not differ from control (Table 2). Similarly, renal function parameters investigated did show any differences as compared to the control groups.

\section{Relative organ weights}

We observed no significant differences between the treated groups and the control group. 
Table 2: Effect of Alchornea cordifolia extract on serum biochemistry of rats treated for two weeks.

\begin{tabular}{lccccc}
\hline & \multicolumn{5}{c}{ Doses $\mathbf{( m g} / \mathbf{k g})$} \\
\cline { 2 - 6 } Parameter & Control & $\mathbf{2 5 0}$ & $\mathbf{5 0 0}$ & $\mathbf{1 0 0 0}$ & $\mathbf{2 0 0 0}$ \\
\hline Total bilirubin & $24.97 \pm 7.72$ & $47.03 \pm 9.21$ & $48.56 \pm 20.31$ & $33.52 \pm 13.60$ & $63.61 \pm 18.00$ \\
( $\mu$ mol/L & & & & & \\
Direct bilirubin & $7.52 \pm 1.92$ & $13.11 \pm 2.45$ & $13.34 \pm 5.76$ & $9.58 \pm 3.65$ & $16.76 \pm 4.73$ \\
$\mu$ mol/L & & & & & \\
Total protein (g/L) & $87.00 \pm 2.30$ & $93.00 \pm 4.57$ & $87.20 \pm 4.63$ & $86.80 \pm 5.54$ & $90.80 \pm 1.93$ \\
Albumin (g/L) & $38.80 \pm 1.59$ & $41.17 \pm 1.11$ & $41.60 \pm 0.40$ & $38.00 \pm 2.55$ & $39.80 \pm 1.02$ \\
Globulin (g/L) & $4.82 \pm 0.27$ & $5.18 \pm 0.39$ & $4.56 \pm 0.43$ & $4.88 \pm 0.37$ & $5.10 \pm 0.13$ \\
Albumin/globulin & $0.82 \pm 0.09$ & $0.82 \pm 0.05$ & $0.94 \pm 0.08$ & $0.80 \pm 0.06$ & $0.78 \pm 0.02$ \\
ratio & & & & & \\
AST (U/L) & $206.80 \pm 27.32$ & $219.80 \pm 15.41$ & $252.80 \pm 14.95$ & $212.80 \pm 16.93$ & $247.00 \pm 22.07$ \\
ALT (U/L) & $88.20 \pm 17.07$ & $99.50 \pm 14.23$ & $116.20 \pm 6.67$ & $101.00 \pm 5.30$ & $112.40 \pm 11.63$ \\
ALP (U/L) & $389.80 \pm 26.04$ & $282.20 \pm 56.42$ & $295.00 \pm 9.64$ & $351.00 \pm 50.00$ & $282.00 \pm 0.00$ \\
GGT (U/L) & $9.60 \pm 0.51$ & $19.17 \pm 5.44$ & $9.67 \pm 3.18$ & $10.75 \pm 2.10$ & $14.50 \pm 3.50$ \\
\hline Values
\end{tabular}

Values are expressed as means \pm SEM $(n=6)$, no significant differences between control and treated groups ( $p>0.05$ ) (Neuman Kuels test)

\section{Histopathological features}

There were no changes in the liver of rats treated with $250 \mathrm{mg} / \mathrm{kg}$ and $500 \mathrm{mg} / \mathrm{kg}$ extract compared to the control (Figure 2). However, in the groups treated with 1000 $\mathrm{mg} / \mathrm{kg}$ and $2000 \mathrm{mg} / \mathrm{kg}$ extract, we observed cloudy swelling of hepatocytes with vacuolar and hydropic degeneration respectively. These changes were diffuse throughout but less severe around the portal tracts as depicted in Figure 2 which is a representative photomicrograph of six animals

As Fig 3 indicates, examination of the kidneys did not show any differences between the extract-treated group and control (at all dose levels).

\section{DISCUSSION}

The therapeutic potential of natural products has increased considerably in recent years with renewed awareness that natural products have the potential to cause toxicity since they contain active constituents [12].
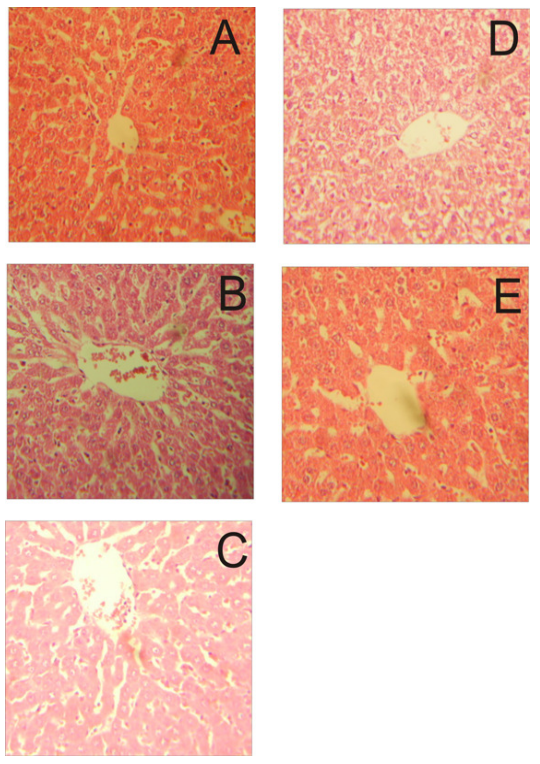

Figure 2: Photomicrograph (x 400) of liver sections of rats treated with Alchornea cordifolia extract for 14 days. Tissues fixed in $10 \%$ neutral buffered formalin were processed and stained with hematoxylin and eosin. Panel A shows the liver section for vehicle-treated control animals, panel B $(250 \mathrm{mg} / \mathrm{kg})$, panel C $(500 \mathrm{mg} / \mathrm{kg})$, panel D (1000 $\mathrm{mg} / \mathrm{kg})$ and panel $E(2000 \mathrm{mg} / \mathrm{kg})$ of extract. In panels $D$ and $E$, cloudy swelling of hepatocytes with vacuolar and hydropic degeneration are seen. The changes are diffused throughout but less severe around the portal tracts 


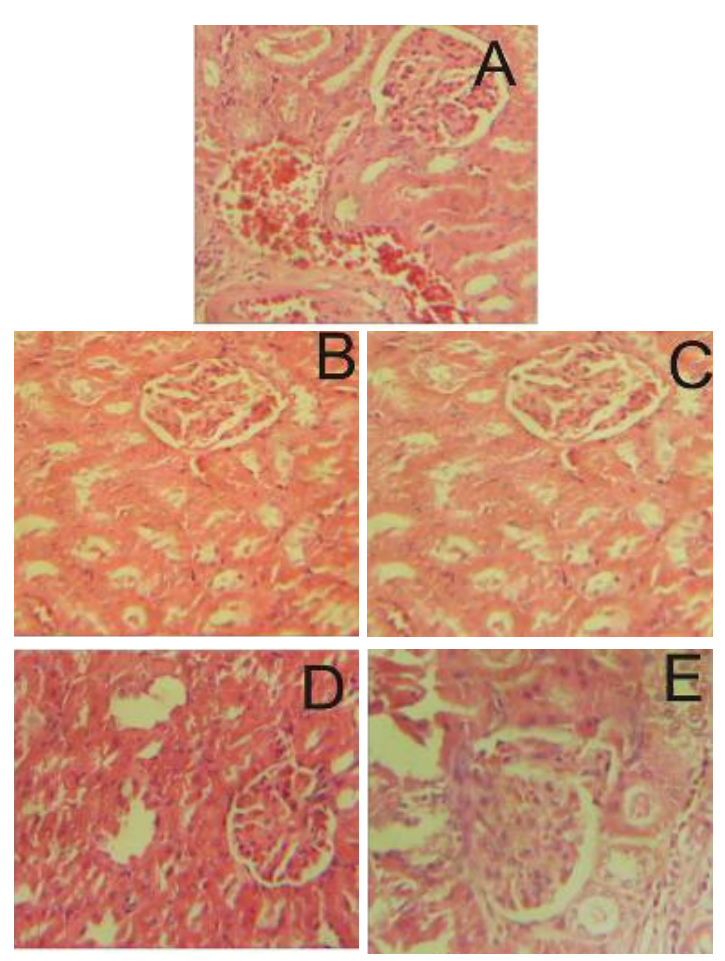

Figure 3: Photomicrograph ( $x$ 400) of kidney sections of rats treated with Alchornea cordifolia extract for 14 days. Tissues fixed in $10 \%$ neutral buffered formalin were processed and stained with hematoxylin and eosin. Panel A shows the kidney section for vehicle-treated control animals, panel $B$ $(250 \mathrm{mg} / \mathrm{kg})$, panel C $(500 \mathrm{mg} / \mathrm{kg})$, panel D (1000 $\mathrm{mg} / \mathrm{kg})$ and panel $E(2000 \mathrm{mg} / \mathrm{kg})$ of extract. No changes were observed in the treatment groups compared to the vehicle-treated control.

There has therefore been a growing interest in the safety assessment of herbal medicines over the past few years.

In the present study, we investigated the possible toxicity of Alchornea cordifolia extract, a potential medicinal agent in rats. Following a 14-day treatment with the extract, the animals were closely monitored for signs of toxicity. Normally, loss of more than $10 \%$ of initial body weight is an indicator of adverse effects [13]. In our study, we did not find significant changes in the body weight or the behavior of the animals. The slight increase in body weight after the 14-day treatment can be ascribed to normal growth of the animals over the period. Food and water intake were normal and no deaths occurred. The relative weights of vital organs of animals did not show significant differences compared to the vehicle-treated control with no evidence of organ swelling, atrophy or hypertrophy in the animals. These observations indicate that our treatment had no effect on the general condition and functional behavior of the animals.

The hematological system has a predictive value for toxicity in humans and therefore analysis of blood is relevant to risk evaluation [14]. Results of the hematological analysis showed that Alchornea cordifolia has little or no effect on white blood cell (WBC), lymphocytes (LYM), mid cells (MID), neutrophils (NEU), red blood cells (RBC), haemoglobin concentration (HB), haematocrit (HCT), mean corpuscular volume (MCV), mean corpuscular haemoglobin $(\mathrm{MCH})$, mean corpuscular haemoglobin concentration (MCHC), red cells distribution weight (RDW) and platelets (PLT). However, a dose dependent increase in neutrophils (NEU) was observed. Neutrophils interact with foreign compounds and microorganisms and destroy them by the process of phagocytosis. They are also known to be involved in the pathology of various inflammatory conditions. It is plausible that the increase in neutrophils in the present study is related to the liver cell injury observed in the histopathological studies. Lymphocytes are also known to circulate in blood and migrate to injured tissues. This may account for the decrease in lymphocyte numbers at the highest dose of treatment.

The markers of renal function, urea and creatinine, were assessed based on reported kidney toxicity associated with the use of medicinal plants [15]. These parameters were not affected in treated animals. Alchornea cordifolia has been shown to contain flavonoids [3]. Some of these flavonoids have been demonstrated to inhibit nephrotoxicity 
because of its strong antioxidant activity [16]. Alchornea cordifolia has also been reported to contain tannins and tannins are known to offer protection against nephrotoxicity [17]. It is possible that these constituents offered protection to the treated animals in the present study.

Aspartate transaminase (AST) and Alanine transaminase (ALT) are considered as indicators of liver function. High levels of AST, ALT and ALP in serum are usually indicative of disease and necrosis in the liver of animals. Alkaline phosphatase (ALP), Gamma glutamyl transpeptidase (GGT), albumin, globulin, bilirubin and total protein were the other biochemical parameters analyzed. Analysis of these parameters is important since there are several reports of liver toxicity related to the use of medicinal plant products [18]. These parameters did not differ in the treated and the vehicle-treated groups, indicating that Alchornea cordifolia caused no adverse effect on the hepatic and renal systems.

Histopathological observations in the liver however did not correlate with the biochemical findings especially at high doses $(1000-2000 \mathrm{mg} / \mathrm{kg})$. At high doses of Alchornea treatment, we observed degenerations in the liver suggesting early signs of liver cell injury. This type of liver injury is however known to be reversible upon withdrawal of the toxicant allowing the liver cells to regenerate. This early stage of liver injury may not necessarily reflect in elevation of liver enzymes.

In contrast to the present findings, Alchornea cordifolia at doses of $200-500 \mathrm{mg} / \mathrm{kg}$ was reported to protect rats against paracetamolinduced liver damage [6]. Alchornea evoked mild liver damage at rather high doses (1000 - $2000 \mathrm{mg} / \mathrm{kg}$ ) in the present work. This may be intriguing but the extract probably contains several components with different pharmacological actions. The proportion of specific toxicants may be increased at high doses. Though the liver damage detected in the histopathology studies was not associated with corresponding elevation of liver transaminases, the potential toxicity of the extract especially at high doses cannot be ignored.

Estimates based on recommended dosage of dried Alchornea cordifolia leaves (maximum $50 \mathrm{~g}$ per litre of water; 4 cups daily) in traditional medicine [19] suggest that humans could take a maximum of $200 \mathrm{mg} / \mathrm{kg}$ of our extract daily. Though this appears to be much lower than the dosages used in the present study, observation of potential liver damage in mice previously [10] and the fact that dosages in herbal remedies are never precise due to non-standardization, call for caution in the routine use of the plant.

\section{CONCLUSION}

The results of the study indicate that though the alcohol extract of Alchornea cordifolia is relatively non-toxic to the haematological and renal systems, it is potentially hepatotoxic in rats if administered at high doses. Though these findings cannot be directly extrapolated to man in view of possible species differences and possible differences in metabolic activation, the present results suggest that caution should be taken in the use of the plant product especially at high doses.

\section{ACKNOWLEDGEMENT}

The authors are grateful to Dr KA Boateng of the Pathology Department, Komfo Anokye Teaching Hospital, Kumasi, Ghana, for assistance in the clinical pathology studies and $\mathrm{Mr}$ Thomas Ansah for technical assistance.

\section{REFERENCES}

1. WHO Geneva, Traditional medicine-growing needs and potential. WHO Policy Perspectives Med. 2002; 2: 1-6

2. Abbiw D.Useful plants of Ghana. London, UK: Intermediate Technology Publications and the Royal Botanic Garden Kew, 1990; p 147 
3. Ogungbamila FO, Samuelsson G. Smooth muscle relaxing flavonoids from Alchornea cordifolia. Acta Pharm Nord 1990; 2: 421-422

4. Lamikanra A, Ogundani AO, Ogungbamila FO. Antibacterial constituents of Alchornea cordifolia leaves. Phytother Res 1990; 4: 198200

5. Mavar-Manga $H$, Haddad $M$, Pieters $L$, Baccelli $C$, Penge A, Quetin-Leclercq, J. Antiinflammatory compounds from leaves and root bark of Alchornea cordifolia (Schumach.\&Thonn.) M"ull. Arg J Ethnopharmacol 2008; 115: 25-29

6. Olaleye MT, Adegboye OO, Akindahunsi $A A$. Alchornea cordifolia extract protects Wistar albino rats against acetaminophen-induced liver damage. Afr J Biotechnol 2006; 5 :24392445

7. Agbor GA, Leopold T, Jeanne NY. The antidiarrhoeal activity of Alchornea cordifolia leaf extract. Phytother Res 2004; 18: 873-876

8. Olaleye MT, Rocha JB. Acetaminophen-induced liver damage in mice: Effects of some medicinal plants on the oxidative defense system. Exp Toxicol Pathol 2008; 59: 319-327

9. Ebi GC. Antimicrobial activities of Alchornea cordifolia. Fitoterapia 2001; 72: 69-72

10. Ansah C, Oppong E, Woode, E, Duwiejua, M. Toxicity studies on Alchornea cordifolia leaf extract in mice. J Sci Tech 2009; 29: 8-16

11. EEC Council directive 86/609/EEC on the approximation of laws, regulations and administrative provisions of the member states regarding the protection of animals used for experimental and other scientific purposes. Official J. Eur Comm 1986; L358: 1-29

12. Bent $S$, Ko R. Commonly used herbal medicines in the United States: a review. Am J Med 2004; 116: 478-485

13. Teo S, Stirling D, Thomas S, Evans MG, Khetani VD. A 90-day oral gavage toxicity study of $d$ methylphenidate and d,l-methylphenidate in Sprague Dawley rats. Toxicology 2002; 179: 183-196

14. Olson $H$, Betton $G$, Robinson D, Thomas $K$, Monro A, Gerald Kolaja G, et al. Concordance of toxicity of pharmaceuticals in humans and in animals. Regul Toxicol Pharmacol 2000; 32: 56-67

15. Isnard BC, Deray G, Baumelou A, Le Quintree M, Vanherweghem J. Herbs and the kidney. Am J Kidney Dis 2004; 44: 1-11

16. Satyanarayana PS, Singh D, Chopra K. Quercetin, a bioflavonoid, protects against oxidative stressrelated renal dysfunction by cyclosporine in rats. Methods Find Exp Clin Pharmacol 2001; 34: 175-181

17. Yokozawa T, Fujioka K, Oura H, Nonaka G, Nishioka I. Effects of rhubarb tannins on uremic toxins. Nephron 1991; 58: 155-160

18. Pittler MH, Ernst E. Systematic review: hepatotoxic events associated with herbal medicinal products. Aliment Pharmacol Ther 2003; 18: 451-471

19. Busia K (Ed). Ghana Herbal Pharmacopoeia. Accra: STERPI. 2007; $p 14$ 